\title{
Mapping Quantitative Trait Loci Responsible for Resistance to Sheath Blight in Rice
}

\author{
G. Liu, Y. Jia, F. J. Correa-Victoria, G. A. Prado, K. M. Yeater, A. McClung, and J. C. Correll
}

First author: Rice Research and Extension Center, University of Arkansas, 2900 Hwy 130E, Stuttgart 72160; second and sixth authors: United States Department of Agriculture-Agricultural Research Service (USDA-ARS), Dale Bumpers National Rice Research Center (DB NRRC), 2890 Hwy 130E, Stuttgart, AR 72160; third and fourth authors: International Center for Tropical Agriculture (CIAT), AA6713, Cali, Colombia; fifth author: USDA-ARS-SPA, 1001 Holleman Drive East, College Station, TX 77840; and seventh author: Department of

Plant Pathology, University of Arkansas, Fayetteville 72201.

Current address of F. J. Correa-Victoria: RiceTec, Inc., P.O. Box 1305, Alvin, TX 77512.

Accepted for publication 15 March 2009.

\section{ABSTRACT}

Liu, G., Jia, Y., Correa-Victoria, F. J., Prado, G. A., Yeater, K. M., McClung, A., and Correll, J. C. 2009. Mapping quantitative trait loci responsible for resistance to sheath blight in rice. Phytopathology 99:1078-1084.

Rice sheath blight (ShB), caused by the soilborne pathogen Rhizoctonia solani, annually causes severe losses in yield and quality in many rice production areas worldwide. Jasmine 85 is an indica cultivar that has proven to have a high level of resistance to this pathogen. The objective of this study was to determine the ability of controlled environment inoculation assays to detect $\mathrm{ShB}$ resistance quantitative trait loci (QTLs) in a cross derived from the susceptible cv. Lemont and the resistant $\mathrm{cv}$. Jasmine 85. The disease reactions of $250 \mathrm{~F}_{5}$ recombinant inbred lines (RILs) were measured on the seedlings inoculated using microchamber and mist-chamber assays under greenhouse conditions. In total, $10 \mathrm{ShB}$ QTLs were identified on chromosomes 1, 2, 3, 5, 6, and 9 using these two methods. The microchamber method identified four of five new ShB-
QTLs, one on each of chromosomes 1, 3, 5, and 6. Both microchamber and mist-chamber methods identified two ShB-QTLs, qShB1 and $q$ ShB92. Four of the ShB-QTLs or ShB-QTL regions identified on chromosomes 2, 3, and 9 were previously reported in the literature. The major ShB-QTL qShB9-2, which cosegregated with simple sequence repeat (SSR) marker RM245 on chromosome 9, contributed to 24.3 and $27.2 \%$ of total phenotypic variation in $\mathrm{ShB}$ using microchamber and mistchamber assays, respectively. $q S h B 9-2$, a plant-stage-independent QTL, was also verified in nine haplotypes of 10 resistant Lemont/Jasmine 85 RILs using haplotype analysis. These results suggest that multiple ShBQTLs are involved in ShB resistance and that microchamber and mistchamber methods are effective for detecting plant-stage-independent QTLs. Furthermore, two SSR markers, RM215 and RM245, are robust markers and can be used in marker-assisted breeding programs to improve $\mathrm{ShB}$ resistance.

Additional keywords: inoculation method, Oryza sativa.
Rice sheath blight ( $\mathrm{ShB}$ ), caused by the soilborne fungal pathogen Rhizoctonia solani Kühn, is one of the most destructive diseases worldwide $(29,30)$. In highly intensive production systems in the United States, ShB disease can cause yield losses up to $50 \%(14,15)$. ShB management typically has relied on the application of fungicides in combination with cultural practices (36). Utilization of host resistance is the most economical and environmentally sound strategy in managing ShB. The ShB pathogen has a broad host range and no complete resistance has been identified in rice germplasm $(17,22)$. However, substantial differences in the levels of susceptibility to the ShB pathogen among rice cultivars have been observed under field conditions $(6,15,16)$. ShB resistance is believed to be controlled by polygenic quantitative trait loci (QTLs) (22). Li et al. (11) first identified ShB-QTLs using restricted fragment length polymorphism (RFLP) markers and field evaluations. Subsequently, a number of QTLs associated with $\mathrm{ShB}$ resistance were identified on rice chromosomes 2, 3, 5, 7, 9, and 11 using segregating $\mathrm{F}_{2}$ populations, double haploid (DH), and recombinant inbred line (RIL) populations under field conditions $(3,5,9,19,22,27,33,38)$. The populations used were mainly derived from the crosses of the ShB-susceptible cv. Lemont with

Corresponding author: Y. Jia; E-mail address: Yulin.Jia@ars.usda.gov

\section{doi:10.1094/PHYTO-99-9-1078}

This article is in the public domain and not copyrightable. It may be freely reprinted with customary crediting of the source. The American Phytopathological Society, 2009. the ShB-resistant cvs. Teqing or Jasmine 85. Pinson et al. (22) confirmed the locations and effects of six previously identified ShB-QTLs and identified eight new ShB-QTLs in an RIL population derived from the cross of Lemont $\times$ Teqing using a field inoculation method. However, the accurate and reliable measurement of ShB resistance in QTL analysis under field conditions is affected by a number of environmental factors, including light intensity, humidity, temperature $(4,10)$, nitrogen fertilizer rate $(28,31)$, and silica level in soil $(25,26)$ as well as plant morphology such as plant height, growth stage, and plant architecture $(1,9,11,26)$.

A number of different inoculation methods have been used to infest field plots for screening for resistance to the ShB pathogen. These methods have included the use of colonized toothpicks inserted into leaf sheaths (38), liquid inoculum injection $(9,27)$, and broadcasting solid inoculum onto rice plants $(3,5,11,15,19$, $22,28,33)$. Other inoculation techniques performed under controlled conditions have included a detached leaf method (7) and a microchamber assay $(2,6,23)$. Different forms of ShB inoculum (grown on agar blocks, liquid cultured mycelia, and mycelia suspension cultures) were also tested in greenhouse studies (20). Jia et al. (6) developed a microchamber method, a simple, rapid, accurate, and reliable method to evaluate varietal resistance to ShB under controlled greenhouse conditions. Compared with inoculated field inoculation screening tests, the controlled environment microchamber assay has the following advantages: (i) younger seedlings used for minimizing the confounding effects of morphological characters on ShB resistance, (ii) 3 to 5 weeks for 
a test, (iii) relatively little experimental space, (iv) year-round greenhouse ShB evaluations, and (v) scoring segregating breeding material or mapping populations by rating individual plants. Similarly, the mist-chamber assay has the advantages in assaying older plants for $\mathrm{ShB}$ resistance in a relatively small space. However, an assay takes a longer time.

The objectives of this study were to (i) map ShB-QTLs identified using two greenhouse inoculation chamber methods and (ii) confirm the identified ShB-QTLs in the resistant RILs from Lemont/Jasmine 85 (LJRILs) for future breeding program in ShB resistance.

\section{MATERIALS AND METHODS}

Plant materials. The RIL population derived from the cross of Lemont $\times$ Jasmine 85 was developed using single-seed descent in a greenhouse at the United States Department of AgricultureAgricultural Research Service Dale Bumpers National Rice Research Center, Stuttgart, AR. Jasmine 85, a long-grain indica rice cultivar developed at the International Rice Research Institute, Philippines, is moderately resistant to ShB (16). Lemont, an early-maturing, semi-dwarf tropical japonica cultivar commercially grown in the southern United States in the 1980s and 1990 s, is susceptible to $\operatorname{ShB}(1,6)$. A subset of $256 \mathrm{~F}_{5}$ RILs from Lemont/Jasmine 85 (LJRILs) was used for constructing a linkage map using 199 simple sequence repeat (SSR) markers. The primer sequences and map positions of the SSR markers were obtained from the Gramene Version 28, September 2008 database (http://www.gramene.org). The SSR markers were selected based on the polymorphism in parental screening at $\approx 10.0$ centimorgans (cM) between the two markers. In total, $250 \mathrm{~F}_{5}$ LJRILs were evaluated under greenhouse conditions for $\mathrm{ShB}$ resistance using a microchamber and mist-chamber assay in a greenhouse at the International Center for Tropical Agriculture (CIAT), Colombia. On both assays, the LJRILs were planted in plastic pots $(15 \mathrm{~cm}$ in diameter) filled with steam-sterilized soil and fertilized with the equivalent of $\mathrm{N}$ at $180 \mathrm{~kg} / \mathrm{ha}, 6 \mathrm{P}$ at $0 \mathrm{~kg} / \mathrm{ha}$, and $\mathrm{K}$ at $60 \mathrm{~kg} / \mathrm{ha}$. Fertilizer applications were split into three equal amounts at the time of planting and at 1 and 2 weeks after planting for the microchamber assay and, for the mist-chamber assay, at the time of planting, 30 days after planting, and 1 day before inoculation. For each fertilizer application, $230 \mathrm{mg}$ of urea $(46 \% \mathrm{~N}), 77 \mathrm{mg}$ of triple superphosphate $\left(46 \% \quad \mathrm{P}_{2} \mathrm{O}_{5}\right)$, and $70 \mathrm{mg}$ of potassium chloride $(50 \% \mathrm{~K})$ were applied to one $15-\mathrm{cm}$ pot.

ShB isolate. The ShB isolate Tol 2399-1 of the pathogen Rhizoctonia solani AG I-1A is one of most aggressive isolate in the most predominant genetic group, no. 9, in Colombia and has a broad spectrum of virulence, causing $>80 \%$ of the disease severity in highly susceptible cultivars such as Lemont (6). Therefore, Tol 2399-1 was selected to use in both chamber assays for ShB resistance. Tol 2399-1 was collected from rice cv. Oryzica 1 in Saldana, Tolima, Colombia in 1993. Tol 2399-1 is stored as mycelium grown on filter paper at $0^{\circ} \mathrm{C}$ and as sclerotia at $4^{\circ} \mathrm{C}$, and maintained in the Rhizoctonia spp. Collection of the Pathology Laboratory at CIAT.

Microchamber assay. A microchamber inoculation assay was used as previously described (6). Actively growing mycelia of Tol 2399-1 from potato dextrose agar (PDA) plates were transferred to fresh PDA medium and cultured for 5 days at $27^{\circ} \mathrm{C}$ under darkness. Mycelial discs ( $7 \mathrm{~mm}$ in diameter) were excised from the culture plate using a pipette tip and were used to inoculate 3 -week-old rice seedlings (four-leaf stage). A colonized disc was placed at the base of each of three rice seedling and the pot was covered with a 3-liter clear plastic bottle whose bottom and cap had been previously removed, forming a microchamber. The inoculated plants were kept at 24 to $28^{\circ} \mathrm{C}$, and evaluated at 8 to 10 days after inoculation or when the susceptible check Lemont exhibited a highly susceptible reaction, where the leaves of in- fected seedlings contained brown lesions and the entire plant became blighted and died, turning straw-colored or light brown. At this time, the resistant cv. Jasmine 85 exhibited a few greengray, water-soaked spots on the leaves and stems. The perforated pots were maintained in flats containing shallow water $(\approx 5 \mathrm{~cm}$ deep) to keep the soil moist during the evaluation period. In a single assay, each pot contained a given LJRIL with three plants per pot. Lemont and Jasmine 85 were included in all experiments as the susceptible and resistant checks, respectively. For each replication, 250 LJRIL entry pots and 4 pots from each of the susceptible and resistant checks were arranged in a completely randomized design. Each assay was then repeated four times (time serves as the random block effect) for a total of four replications. The replications were conducted at different dates during February and March 2007. The greenhouse temperatures for day and night averaged at 30 and $21^{\circ} \mathrm{C}$, respectively.

$\mathrm{ShB}$ severity of an individual test plant was estimated using the percentage of the diseased plant area affected (DPAA). For this purpose, on a 3-week-old seedling containing three leaves, a maximum disease severity value of $30 \%$ was assigned to the first or oldest leaf; a maximum disease severity of $25 \%$ was assigned to each of the two following leaves, and a maximum of $20 \%$ to the stem, for a possible total of $100 \%$. For example, if the oldest leaf was half covered with $\mathrm{ShB}$ symptoms, a disease severity of $15 \%$ was assigned to this leaf, and if the stem was only half covered with ShB symptoms, a disease severity of $10 \%$ was assigned to the stem. The disease severity of a test plant was estimated as the sum of the individual severities assigned to each one of the three leaves and the stem of the seedling.

Mist-chamber assay. Inoculum was prepared using the same procedure as described above for the microchamber assay. Rice plants were grown in $15-\mathrm{cm}$ plastic pots placed in a walk-in plastic chamber (4-by-3-by-2 $\mathrm{m}$ with a capacity of 500 pots) at $>95 \%$ relative humidity. The high humidity was generated by three Herrmidifier 707-U humidifiers (Effingham, IL) in a chamber. Fifty days after sowing (flag leaf well developed), a colonized mycelial disc was placed at the base of each rice plant in each pot. The inoculated plants were incubated in the mist chamber for 10 days, transferred onto a greenhouse bench, and left for 5 days. The plants were moved back to the mist chamber for another 5 days in the second incubation period. In a single assay, each pot contained a given LJRIL with five plants per pot. Lemont and Jasmine 85 were included in all experiments as the susceptible and resistant checks, respectively. In a replication, 250 LJRIL entry pots and 2 pots from each of the susceptible and resistant checks were arranged in a completely randomized design. Each assay was then repeated five times (time serves as the random block effect), making for a total of five replications. The replications were conducted at different dates during February and June 2007. The average temperature within the mist chamber was maintained at 21 to $35^{\circ} \mathrm{C}$.

ShB severity of an individual test plant was also estimated using DPAA. For this purpose, on a 50-day-old plant containing five leaves on the main tiller, a maximum disease severity value of $30 \%$ was assigned to the first leaf; $15 \%$ to each of the second and third leaves, $10 \%$ to each of the fourth and fifth leaves, and $20 \%$ to the stem, for a possible total of $100 \%$. For example, if the oldest leaf was half covered with ShB symptoms, a disease severity of $15 \%$ was assigned to this leaf and, if the stem was only half covered with ShB symptoms, a disease severity of $10 \%$ was assigned to the stem. The disease severity of the test plant was then estimated as the sum of the individual severities assigned to each one of the five leaves and the stem of the plant.

Statistical analysis of phenotypic data. The ShB severity ratings from three individual plants (microchamber assay) or five individual plants (mist-chamber assay) in a pot were averaged as a replicate for calculating the least square means (LSMs) and standard errors. The LSMs of the ShB severity of the LJRILs 
were determined using the GLIMMIX procedure in SAS (version 9.1.3; SAS Institute, Cary, NC). The LSMEANS option was used to calculate the estimated means and standard errors of the LJRILs and checks. The statistical model for each assay included the fixed effect of the LJRILs and checks and the random block effect of time. Within a chamber assay, the distribution of measured variable and residuals were assessed and determined to fit a Gaussian (normal) curve. Correlation analysis of the two chamber assays was performed using the LSMs in the CORR procedure of SAS (version 9.1.3).

DNA marker genotyping and the construction of an SSR map. DNA extraction of 256 LJRILs followed the method as described by Tai and Tanksley (32). Five to nine fresh rice leaves of each LJRIL were collected and ground. Total genomic DNA was extracted and normalized to $5 \mathrm{ng} / \mu \mathrm{l}$ for SSR amplification. The conditions of SSR amplification and allele determination were previously described by Liu et al. (12). More than 270 SSR markers which evenly covered 12 rice chromosomes at $\approx 10 \mathrm{cM} /$ marker were screened to identify polymorphism between the parents of Lemont and Jasmine 85, and 199 polymorphic SSR markers were found. The amplified polymerase chain (PCR) reaction products were pooled and separated on an ABI Prism 3700 DNA analyzer. The sizes of SSR fragments were determined using the software GeneScan and Genotyper, version 3.7NT (Applied Biosystem Inc., Foster City, CA).

An SSR linkage map comprising 199 SSR markers was constructed using JoinMap 4 based on the Kosambi function (8). Loci were assigned to linkage groups by the program default settings and likelihood odds ratio (LOD) scores were $\geq 3.0$. The "fix order" command was used to identify the most likely marker order within a group when needed. The constructed SSR map represents a total of $1,684.2 \mathrm{cM}$ of the genetic distance at an average of $8.5 \mathrm{cM}$ between linked marker loci.

Data analysis and QTL mapping. The mean ShB severity for the LJRILs was used for the composite interval mapping (CIM). QTL analysis was performed using Windows QTL Cartographer, version 2.5 (35), with the default CIM control parameters model 6 of standard model, five control markers, $10 \mathrm{cM}$ of window size, and forward regression method. The LOD threshold of $\geq 2.4$ was used to declare the presence of a putative QTL in order to compare with the previously identified ShB-QTLs on rice chromosomes $(3,5,9,19,22,27,33,38)$. Additive effect and percentage of variation explained by individual ShB-QTLs were estimated.

\section{RESULTS}

Variability in ShB severity in the LJRIL population. The resistant check Jasmine 85 and susceptible Lemont had significantly different ShB ratings in the microchamber assay $(P=$ $0.0004)$ and mist-chamber assay $(P<0.0001)$ (Table 1). Jasmine 85 and Lemont had consistent reactions to the pathogen in both chamber assays. The DPAA of each replicate varied at 90.0 to 94.0 and 60.0 to $90.0 \%$ for Lemont and 45.0 to 55.0 and 36.4 to $46.4 \%$ for Jasmine 85 in the microchamber and mist-chamber assays, respectively. Jasmine 85 had a similar deviation of LSMs, indicating that it had more stable performance in both assays than Lemont. The relatively small standard errors for the means of the LJRIL population indicated that the phenotypic variation in ShB severity ratings between replicates was acceptable for QTL mapping (Table 1). This finding ruled out the potential artifacts contributed by the small percentage of the heterozygosity in the $\mathrm{F}_{5}$ LJRIL population used for this study. In comparison with the microchamber assay, the lower standard error for the population mean in the mist-chamber assay demonstrated a higher precision between replicates, likely due to more replicates and individual rice plants being used (Table 1). The fixed effects from the LJRILs were statistically significantly different in both chamber assays. The random effect due to the time block (replication) was more variable in the mist chamber assay than in the microchamber assay (data not shown).

The mean ShB severity on the LJRILs in the microchamber and mist-chamber assays was distributed normally, with the resistant and susceptible parents at the extreme ends (Fig. 1). The microchamber assay for evaluating ShB resistance was very comparable with the mist-chamber assay. The linear correlation for the mean severity of the LJRILs between two assays was positive, with the correlation coefficient of $r=0.62(P<0.0001, n=252)$ (Fig. 2).

QTL mapping for ShB resistance. An SSR map was constructed for QTL analysis using 256 LJRILs and 199 SSR markers evenly distributed over the 12 rice chromosomes. The identified ShB-QTLs responsible for ShB resistance using the two types of incubation assays are summarized in Table 2 and Figure 3. Six ShB-QTLs of $q S h B 1, q S h B 3-1, q S h B 5, q S h B 6, q S h B 9-1$, and $q S h B 9-2$ identified using the microchamber method were located on chromosome 1, 3, 5, 6, and 9. Using the mist chamber method, six ShB-QTLs were mapped on chromosome 1, 2, 3, and 9, referred to as $q S h B 1, q S h B 2-1, q S h B 2-2, q S h B 3-2, q S h B 3-3$, and $q S h B 9-2$. Except for $q S h B 9-2$, all the individual ShB-QTLs in both chamber assays could explain a range of 3 to $6.9 \%$ of total phenotypic variation (Table 2). However, one major ShB-QTL of qShB9-2 was identified using both the micro- and mist-chamber assays and had LOD values of 17.3 and 19.9, respectively. The resistant allele of $q S h B 9-2$ from Jasmine 85 explained $24.3 \%$ of total phenotypic variation, with an additive effect of 8.06 when $\mathrm{ShB}$ was evaluated using the microchamber assay, and $27.2 \%$ of total phenotypic variation with an additive effect of 5.75 using the mist-chamber assay (Table 2). RM215 and RM245 flanked $q S h B 9-2$ (Fig. 3). Similarly, $q S h B 1$ was also identified by both incubation chamber assays on chromosome 1 , and was flanked by RM1361 and RM104 (Fig. 3). qShB3-1 detected by the microchamber and $q S h B 3-2$ by the mist chamber were located in a QTL region between RM16 and RM426 on chromosome 3. Resistant alleles at $q S h B 5, q S h B 6$, and $q S h B 9-1$ from the ShB-susceptible parent Lemont were identified only using the microchamber method, and accumulated $19.0 \%$ of total phenotypic variation and $-14.51 \%$ of additive effects (Table 2 ).

Confirmation of identified ShB-QTLs in LJRILs for marker-assisted breeding. All the resistant LJRILs selected were found to contain the major ShB-QTL $q S h B 9-2$ (Table 3). Six

TABLE 1 . Summary of the diseased plant area affected (DPAA) (\%) by rice sheath blight (ShB) on the recombinant inbred lines of Lemont $\times$ Jasmine 85 and the susceptible and resistant checks assayed in Colombia, 2007 ${ }^{\mathrm{x}}$

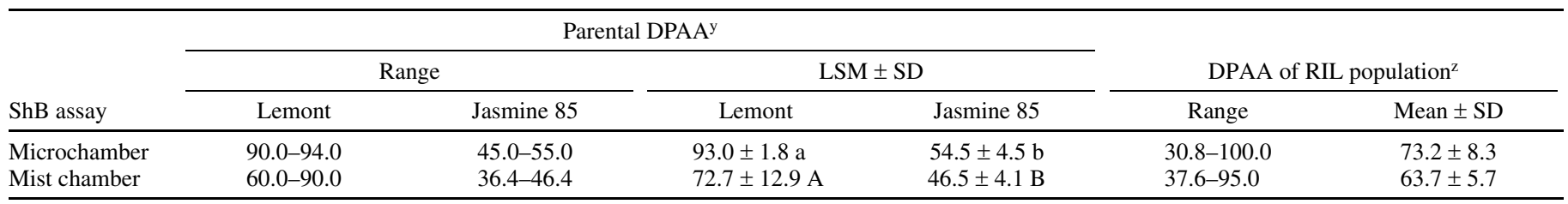


assay). Averages from three ShB severity ratings in a pot (replicate).

y Shown are range of Lemont (susceptible check) and Jasmine 85 (resistant check) and least square means (LSD) \pm standard deviation (SD).

${ }^{z}$ Recombinant inbred line (RIL) population sizes were 252 for microchamber assay and 258 for mist-chamber assay (including 6 local ShB-resistant checks). 
ShB-QTLs of $q S h B 1, q S h B 2-1, q S h B 3-1, q S h B 3-2, q S h B 3-3$, and $q S h B 6$ were commonly presented in most of the LJRILs. Six LJRILs of LJRIL142, LJRIL158, LJRIL186, LJRIL190, LJRIL215, LJRIL221, and LJRIL246 were homozygous at all loci. Nine haplotypes were found in the LJRILs based on allelic comparison (Table 3). LJRIL158 and LJRIL 215 belonged to one haplotype.

\section{DISCUSSION}

The absence of complete resistance to $\mathrm{ShB}$ in Oryza sativa has prevented the use of such genes for managing ShB (17). ShB resistance is considered to be a multigenic trait, making it difficult to evaluate the effect of individual QTLs on resistance. Inoculated field trials have been used for phenotypic evaluations of ShB resistance in previous QTL mapping studies $(3,5,9,19,22,27$, $33,38)$. The accuracy of such an approach for QTL mapping can be confounded by a number of variables, including environmental factors under field conditions (13,21). Pinson et al (22) suggested that the accuracy of ShB phenotyping could be confounded by variable humidity and temperature in the plant microenvironment under field conditions during ShB disease development. Factors such as plant density, tiller number, lodging, and water depth can all affect the plant microenvironment. Plant height and heading date were also reported as confounding factors associated with mapping ShB-QTLs $(9,11,13,22,27,38)$. In the present study, such confounding factors that may influence the accuracy of mapping ShB-QTLs can be ruled out because young rice plants were used for both assays under controlled environmental conditions.

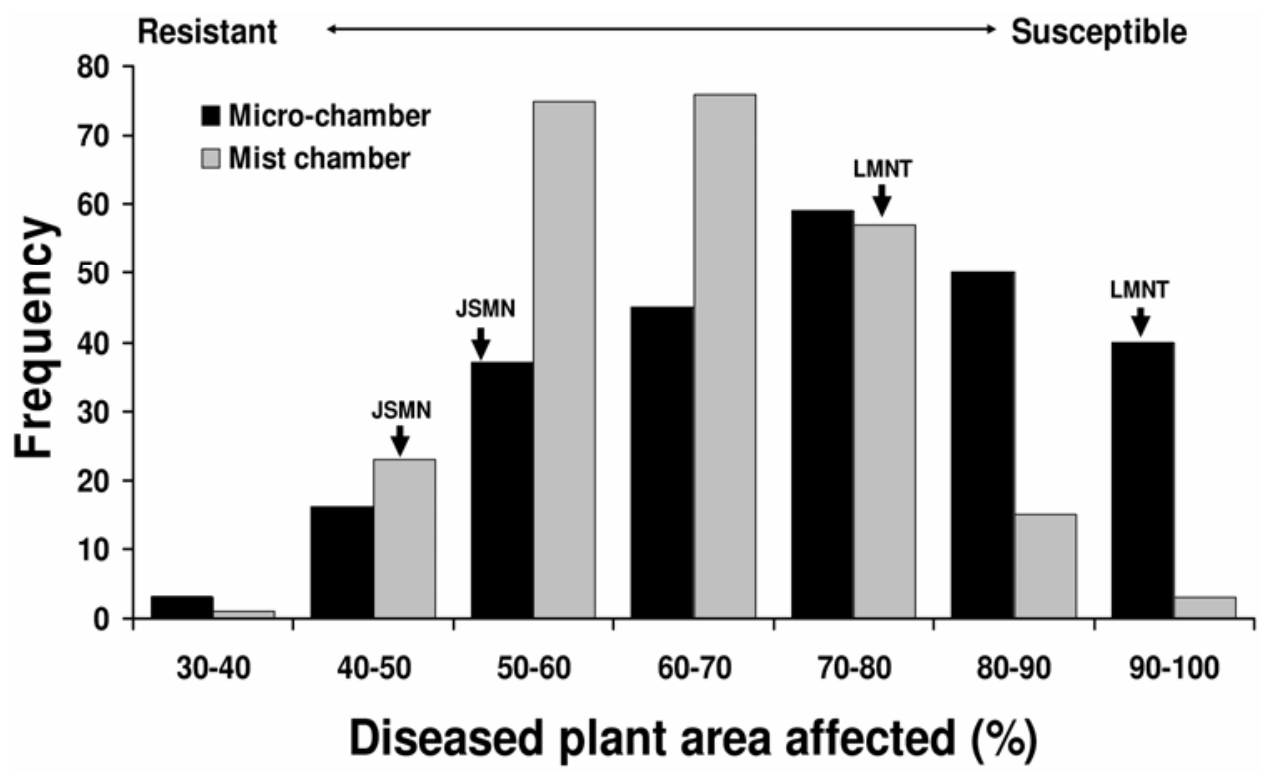

Fig. 1. Frequency distribution of the least square means of the diseased plant area affected in percentage of 250 recombinant inbred lines from the cross of Lemont (LMNT) and Jasmine 85 (JSMN) assayed in greenhouse for sheath blight resistance using microchamber and mist-chamber methods. Arrows show the relative positions of the resistant JSMN and susceptible LMNT parents.

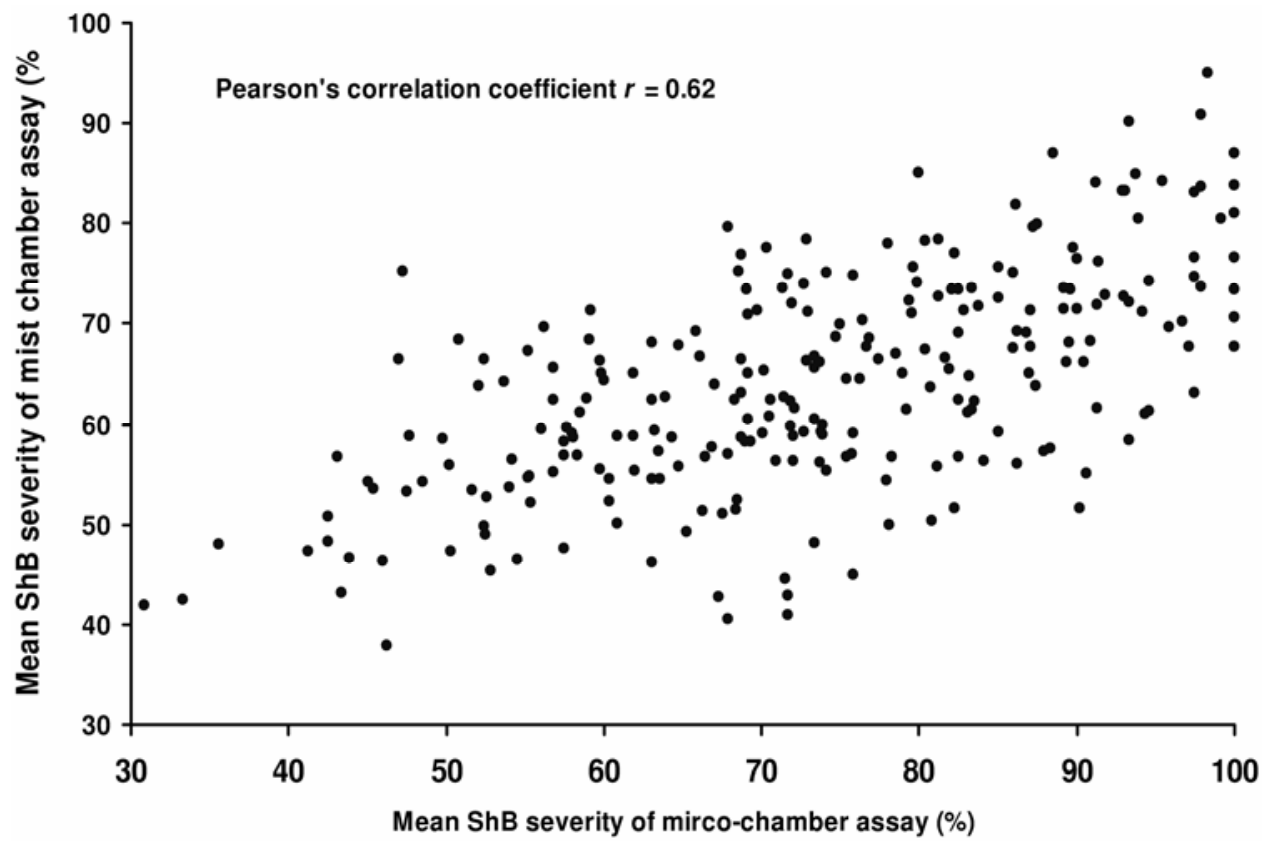

Fig. 2. Scatter plot and Pearson's correlation coefficient based on the correlation analysis of the two chamber assays for sheath blight (ShB) resistance. Least square means from the recombinant inbred lines population of Lemont/Jasmine 85 were used for plotting. 
TABLE 2. Summary of quantitative trait loci (QTLs) analysis for the resistance to rice sheath blight (ShB) using composite interval mappingx

\begin{tabular}{|c|c|c|c|c|c|c|}
\hline ShB evaluation assay, ShB-QTL & Chromosome & Marker interval & Nearest marker locus & $\begin{array}{l}\text { LOD } \\
\text { value }^{\mathrm{y}}\end{array}$ & $\begin{array}{c}\text { Phenotypic } \\
\text { variation (\%) }\end{array}$ & $\begin{array}{c}\text { Additive } \\
\text { effect }^{\mathrm{Z}}\end{array}$ \\
\hline \multicolumn{7}{|l|}{ Microchamber } \\
\hline$q \operatorname{ShB} 1$ & 1 & RM1361-RM104 & RM104 & 3.2 & 3.4 & 2.98 \\
\hline$q \operatorname{ShB3}-1$ & 3 & RM16-RM426 & RM5626 & 2.8 & 3.7 & 3.24 \\
\hline$q \operatorname{ShB5}$ & 5 & RM507-RM7349 & RM13 & 4.4 & 5.1 & -3.67 \\
\hline$q \operatorname{Sh} B 6$ & 6 & RM435-RM190 & RM190 & 2.7 & 3.4 & -2.90 \\
\hline$q \operatorname{Sh} B 9-1$ & 9 & RM409-RM257 & RM434 & 4.7 & 5.4 & -4.27 \\
\hline$q \operatorname{Sh} B 9-2$ & 9 & RM215-RM245 & RM245 & 17.3 & 24.3 & 8.06 \\
\hline \multicolumn{7}{|l|}{ Mist chamber } \\
\hline$q S h B 1$ & 1 & RM1361-RM104 & RM104 & 3.0 & 3.6 & 2.13 \\
\hline$q S h B 2-1$ & 2 & RM424-RM5427 & RM341 & 6.1 & 6.9 & 2.95 \\
\hline$q S h B 2-2$ & 2 & RM112-RM250 & RM250 & 2.6 & 3.2 & 1.96 \\
\hline$q \operatorname{ShB} 3-2$ & 3 & RM5626-RM426 & RM426 & 2.6 & 3.3 & 2.19 \\
\hline$q \operatorname{ShB} 3-3$ & 3 & RM514-RM85 & RM85 & 2.8 & 3.0 & 2.07 \\
\hline$q \operatorname{Sh} B 9-2$ & 9 & RM215-RM245 & RM245 & 19.9 & 27.2 & 5.75 \\
\hline
\end{tabular}

x ShB resistance was phenotyped using micro-chamber and mist chamber assays in Colombia, 2007.

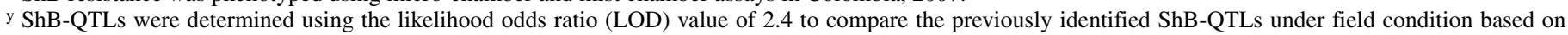
the reports on ShB-QTL mapping $(3,5,9,19,22,27,33,38)$.

z Additive effect is the effect associated with substitution of a Jasmine 85 allele by its corresponding Lemont allele.

Chr.1

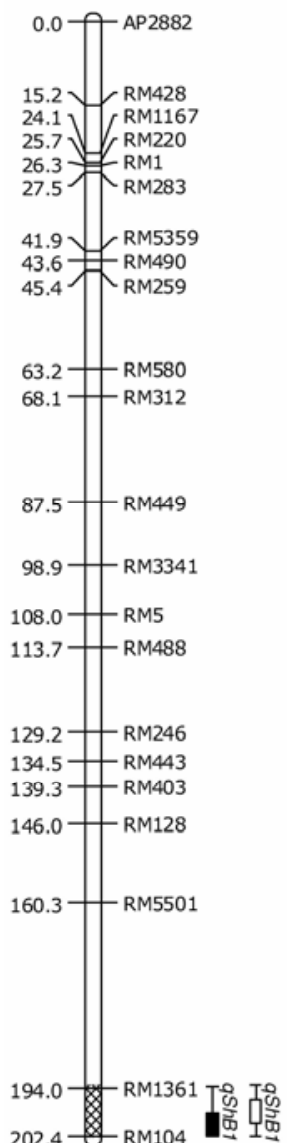

$202.4-$ RM104
Chr.2

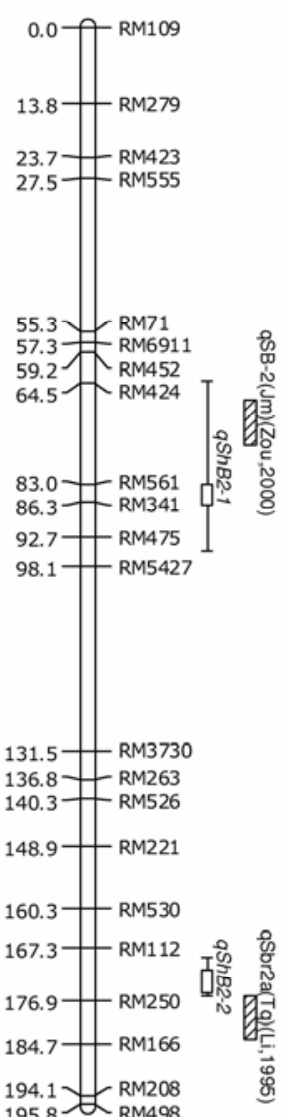

$194.1 \mathcal{L}_{\text {RM498 }}^{\text {RM208 }}$
Chr.3

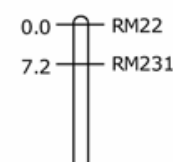

\begin{tabular}{l|r}
27.9 & RM489 \\
36.1 & RM545 \\
42.4 & RM517
\end{tabular}

\begin{tabular}{l|l}
$42.4-$ RM517 \\
$46.3-$ OSR13
\end{tabular}

$59.0 \sqrt{ }{ }^{\mathrm{RM} 7}$

59.4 RM232

60.0 RM251

$72.2-\mathrm{RM} 282$

\begin{tabular}{l|l}
86.7 & RM338
\end{tabular}

107.2 MRG6395

109.0 MRG4864

110.1 RM156

112.8
RM16
RM5626

134.2- RM426

142.0 RM55

142.8 RM15824

159.6 RM293

165.8 RM468

168.9 RM422

168.9 RM422

$179.9 \sqrt{\text { RM514 }}$

184.1 . RM442
Chr.5

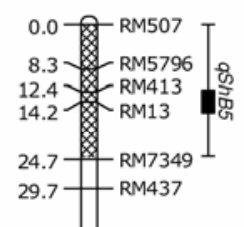

$53.4-$ RM169

59.9- RM509

80.8 $\mid \begin{array}{r}\mid \\ \text { RM164 }\end{array}$

89.1 - RM459

93.8- RM161

99.4- RM5401

$107.6-$ RM421

121.6- RM26

127.5- RM87

\section{Chr.6}

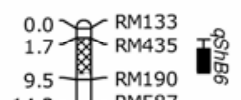

$9.5-14.8190$

14.2 Z RM587

21.5 - RM225

37.1 - RM253

25.5 R136

57.3 ${ }_{\text {RM3431 }}$

$64.7-$ RM3183

69.9 RM541

72.6 RM7193

$85.2-$ RM454

$91.3-$ RM162

105.4 RM5371

$121.2-\mathrm{RM} 340$

$135.3-$ RM103
Chr.9

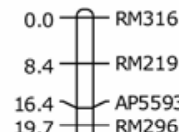

$19.7-$ RM296

22.8 RM105

RM409

$67.2+$ RM108

$71.1-$ RM107

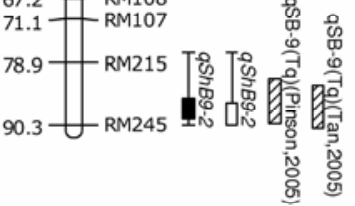

\&

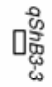

ShB-QTLs identified using micro-chamber

ShB-QTLs identified using mist chamber

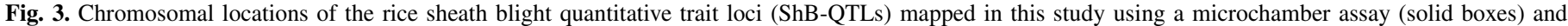

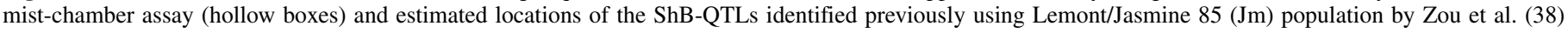

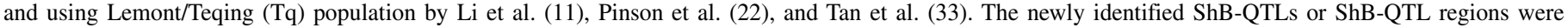
indicated on chromosome (Chr.) bars using a cross-hatched pattern.

The resistant alleles at the $q S h B 3-1$ and $q S h B 3-2$ loci from Jasmine 85 detected using both assay methods confirmed the existence of the ShB-QTL $q S B-3$ identified using an $\mathrm{F}_{2}$ clonal population derived from the cross of Lemont $\times$ Jasmine 85 by Zou et al. (38) (Fig. 2). Furthermore, the location of qShB2-1 on chromosome 2 detected using the mist chamber was near the locus of $q S B-2$ previously identified by Zou et al. (38). In addition, $q S h B 9-1$ originating from Lemont was located on chro- mosome 9 in the present study. Zou et al. (38) previously mapped Lemont-originated $q S B-9-2$ at different location on chromosome 9 using a different fungal isolate (Fig. 2). Whether $q \operatorname{ShB} 9-1$ is allelic to $q S B-9-2$ needs further verification. However, our results confirm the existence of the major ShB-QTL $q S h B 9-2$ conferring partial resistance to $\mathrm{ShB}$ in seedling (chamber assays) and adult plant (field evaluation) stages, which has been reported from the analyses of various mapping populations at different locations 
TABLE 3. Confirmation of the presence of rice sheath blight quantitative trait loci (ShB-QTLs) with the resistant phenotype in selected recombinant inbred lines from Lemont/Jasmine 85 (LJRILs) for marker-assisted breeding

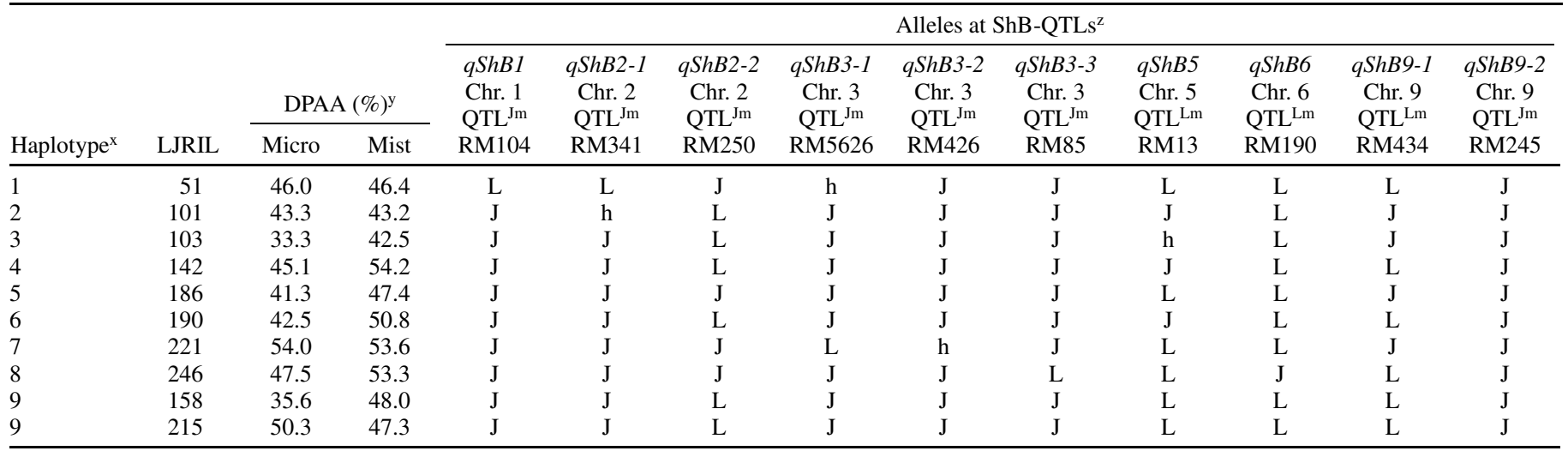

${ }^{x}$ Haplotype was selected based on $<55 \%$ of the DPAA percentages and $100 \%$ SSR amplification.

y Percent diseased plant area affected (DPAA) for average of four and five replicates for microchamber (Micro) and mist-chamber (Mist) assays, respectively.

${ }^{\mathrm{z}}$ Letters L, J, and $\mathrm{h}$ stand for the parents Lemont and Jasmine 85 and heterozygous alleles, respectively. Each ShB-QTL is followed by its chromosome (Chr.) number, the indication of the resistant allele origination from either Jasmine $85\left(\mathrm{QTL}^{\mathrm{Jm}}\right)$ or Lemont (QTL $\left.{ }^{\mathrm{Lm}}\right)$, and the nearest simple sequence repeat (SSR) marker.

using different evaluation methods $(22,33)$. These findings suggest that $q S h B 9-2$ identified in different plant growth stages is a plant-stage-independent QTL. ShB-QTL $q$ ShB2-2, mapped using the mist-chamber assay on chromosome 2 in the present study, was close to $q S b r 2 a$ identified using bulk $\mathrm{F}_{4}$ population of Lemont $\times$ Teqing (11). The major QTL $q S h B 9-2$ on chromosome 9 was mapped between markers RM215 and RM245, representing a region of $\approx 12 \mathrm{cM}$ in the present study. The same QTL was also identified from Teqing using the $F_{10-11}$ RIL population of Lemont $\times$ Teqing (22) and using the $F_{2}$ clonal population of Lemont $\times$ Teqing (33). These observations suggest that the same major QTL derived from these two indica genotypes.

In the present study, some of ShB-QTLs were identified using the microchamber assay ( $q S h B 3-1, q S h B 5, q S h B 6$, and $q S h B 9-1)$ and others were identified using the mist-chamber assay ( $q S h B 2$ 1, $q S h B 2-2, q S h B 3-2$, and $q S h B 3-3)$. Using both chamber assays, four new ShB-QTLs- $q S h B 1, q S h B 3-3, q S h B 5$, and $q S h B 6$ on chromosomes 1, 3, 5, and 6-were identified and some of these new QTLs may be plant-stage dependent. The discovery of these QTLs suggests that each of the inoculation methods can detect the major, unique ShB-QTLs and ones which may not be detected under field evaluations, such as the plant-stage-dependent QTLs. Similarly, the plant-stage dependent QTLs were previously identified in partial resistance to leaf rust in barley (24) and tiller number of rice (37). Hence, both micro- and mist-chamber assays are useful for identifying the major or plant-stage-independent ShB-QTLs in early growth stages of rice plants. Taken together, the greenhouse and field $\mathrm{ShB}$ evaluation methods are recommended for tagging all possible ShB-QTLs.

Fine mapping and cloning the genes for ShB resistance is the next important step for understanding resistance mechanisms and increasing selection precision using marker-assisted selection (MAS). A number of defense genes have recently been identified in cv. Jasmine 85 within $48 \mathrm{~h}$ of infection by the pathogen $R$. solani using the robust long-serial analysis of gene expression and microarray analysis (34). A number of nucleotide binding site leucine-rich repeat candidate genes for ShB resistance and 400 highly expressed rice genes following pathogen infection were also recently identified on several chromosomes where ShBQTLs were determined using the present greenhouse methods (M. Jia and Y. Jia, unpublished data).

Two common problems for using MAS for ShB QTL are (i) DNA markers may not be distinguishable in different germplasm and (ii) phenotypic evaluation methods are too inaccurate to verify genetic resistance (18). Mapping and confirmation of a major ShB-QTL on chromosome 9 and resistant LJRILS with the majority of ShB-QTLs identified in the present study are important advances for using MAS in breeding for ShB resistance (18). Recently, Zuo et al $(39,40)$ demonstrated the potential for deploying indica resistance ShB-QTLs of $q S B-9$ and $q S B-11$ to improve japonica germplasm. The markers RM215 and RM245 identified in this study, in combination with microchamber and mist-chamber assays, are excellent new tools for implementing MAS for improving ShB resistance in rice-breeding programs. In addition, we have identified other minor ShB-QTLs, some even contributed by the susceptible parent, which can be used to develop new cultivars with improved resistance to this important disease.

\section{ACKNOWLEDGMENTS}

This work was supported in part by the United States Department of Agriculture (USDA) Cooperative State Research, Education and Extension Service-National Research Initiative-Applied Plant Genomics Program entitled "RiceCAP: a coordinated research, education, and extension project for the application of genomic discoveries to improve rice in the United States" (USDA/CSREES grant 2004-35317-14867). We thank M. H. Jia for assistance in genotyping; G. Aricapa and L. Rosero for assistance in greenhouse evaluation of ShB resistance; S. Savary and L. Savary, International Rice Research Institute, Manila, Philippines, for critical reading of the manuscript; and J N. Rutger for his encouragement and support on this research.

\section{LITERATURE CITED}

1. Bollich, C. N., Webb, B. D., Marchetti, M. A., and Scott, J. E. 1985. Registration of 'Lemont' rice. Crop Sci. 25:883-885.

2. Castilla, N. P., Leaño, R. M., Elazegui, F. A., Teng, P. S., and Savary, S. 1996. Effects of plant contacts, inoculation pattern, leaf wetness regime, and nitrogen supply on inoculum efficiency in rice sheath blight. J. Phytopathol. 144:187-192.

3. Che, K. P., Zhan, Q. C., Xing, Q. H., Wang, Z. P., Jin, D. M., He, D. J., and Wang, B. 2003. Tagging and mapping of rice sheath blight resistance gene. Theor. Appl. Genet. 106:293-297.

4. Eizenga, G. C., Lee, F. N., and Rutger, J. N. 2002. Screening Oryza species plants for rice sheath blight resistance. Plant Dis. 86:808-812.

5. Han, Y. P., Xing, Y. Z., Chen, Z. X., Gu, S. L., Pan, X. B., Chen, X. L., and Zhang, Q. F. 2002. Mapping QTL for horizontal resistance to sheath blight in an elite restorer line Minghui 63. Chin. J. Genet. 29:622-626. (In Chinese with English abstract)

6. Jia, Y., Correa-Victoria, F., McClung, A., Zhu, L., Liu, G., Wamishe, Y., Xie, J., Marchetti, M. A., Pinson, S. R. M., Rutger, J. N., and Correll, J. C. 2007. Rapid determination of rice cultivar response to the sheath blight pathogen Rhizoctonia solani using a micro-chamber screening method. Plant Dis. 91:485-489.

7. Jia, Y., Singh, P., Eizenga, G. C., Lee, F. N., and Cartwright, R. D. 2002. 
In vitro identification of cultivar responses to rice sheath blight pathogen Rhizoctonia solani. Pages 229-236 in: B. R. Wells Rice Research Studies 2002, Arkansas Agricultural Experimental Station Research Series 504 (http://arkansasagnews.uark.edu/1321.htm)

8. Kosambi, D. D. 1944. The estimation of map distances from recombination values. Ann. Eugen. 12:172-175.

9. Kunihiro, Y., Qian, Q., Sato, H., Teng, S., Zeng, D. L., Fujimoto, K., and Zhu, L. H. 2002. QTL analysis of sheath blight resistance in rice (Oryza sativa L.). Chin. J. Genet. 29:50-55. (In Chinese with English abstract)

10. Lee, F. N., and Rush, M. C. 1983. Rice sheath blight: a major rice disease. Plant Dis. 67:829-832.

11. Li, Z. K., Pinson, S. R. M., Marchetti, M. A., Stansel, J. W., and Park, W. D. 1995. Characterization of quantitative trait loci (QTL) in cultivated rice contributing to field resistance to sheath blight (Rhizoctonia solani). Theor. Appl. Genet. 91:382-388.

12. Liu, G., Bernhardt, J. L., Jia, M. H., Wamishe, Y. A., and Jia, Y. 2008. Molecular characterization of the recombinant inbred line population derived from a japonica-indica rice cross. Euphytica 159:73-82.

13. Lu, C., Shen, L., Tan, Z., Xu, Y., He, P., Chen, Y., and Zhu, L. 1996. Comparative mapping of QTL for agronomic traits of rice across environments using a doubled haploid population. Theor. Appl. Genet. 93:1211-1217.

14. Marchetti, M. A. 1983. Potential impact of sheath blight on yield and milling quality of short-stature rice lines in the southern United States. Plant Dis. 67:162-165.

15. Marchetti, M. A., and Bollich, C. N. 1991. Quantification of the relationship between sheath blight severity and yield loss in rice. Plant Dis. 75:773-775.

16. Marchetti, M. A., Bollich, C. N., Webb, B. D., Jackson, B. R., McClung, A. M., Scott, J. E., and Hung, H. H. 1998. Registration of 'Jasmine 85' rice. Crop Sci. 38:896.

17. Mew, T. W., Leung, H., Savary, S., Vera Cruz, C. M., and Leach, J. E. 2004. Looking ahead in rice disease research and management. CRC Crit. Rev. Plant Sci. 23:103-127.

18. Pan, X., Zhang, Y., Zuo, S., and Chen, Z. 2005. Discussion on QTL identification and application for important quantitative traits in crops. J. Yangzhou Univ. (Agric. Life Sci.) 26:50-55. (In Chinese with an English abstract)

19. Pan, X. B., Rush, M. C., Sha, X. Y., Xie, Q. J., Linscombe, S. D., Stetina, S. R., and Oard, J. H. 1999. Major gene, nonallelic sheath blight resistance from the rice cultivars Jasmine 85 and Teqing. Crop Sci. 39:338-346.

20. Park, D., Sayler, R. J., Hong, Y., Nam, M., and Yang, Y. 2008. A method for inoculation and evaluation of rice sheath blight disease. Phytopathology 92:25-29.

21. Paterson, A. H., Damon, S., Hewitt, J. D., Zamir, D., Rabinowitch, H. D., Lincoln, S. E., Lander, E. S., and Tanksley, S. D. 1991. Mendelian factors underlying quantitative traits in tomato: comparison across species, generations, and environments. Genetics 127:181-197.

22. Pinson, S. R. M., Capdevielle, F. M., and Oard, J. H. 2005. Confirming QTL and finding additional loci conditioning sheath blight resistance in rice using recombinant inbred lines. Crop Sci. 45:503-510.

23. Prasad, B., and Eizenga, G. C. 2008. Rice sheath blight disease resistance identified in Oryza spp. accessions. Plant Dis. 92:1503-1509.

24. Qi, X., Niks, R. E., Stam, P., and Lindhout, P. 1998. Identification of QTLs for partial resistance to leaf rust (Puccinia hordei) in barley. Theor. Appl. Genet. 96:1205-1215.
25. Rodrigues, F. Á., Datnoff, L. E., Korndörfer, G. H., Seebold, K. W., and Rush, M. C. 2001. Effect of silicon and host resistance on sheath blight development in rice. Plant Dis. 85:827-832.

26. Rodrigues, F. Á., Vale, F. X. R., Datnoff, L. E., Prabhu, A. S., and Korndörfer, G. H. 2003. Effect of rice growth stages and silicon on sheath blight development. Phytopathology 93:256-261.

27. Sato, H., Ideta, O., Ando, I., Kunihiro, Y., Hirabayashi, H., Iwano, M., Miyasaka, A., Nemoto, H., and Imbe, T. 2004. Mapping QTL for sheath blight resistance in the rice line WSS2. Breed. Sci. 54:265-271.

28. Savary, S., Castilla, N. P., Elazegui, F. A., McLaren, C. G., Ynalvez, M. A., and Teng, P. S. 1995. Direct and indirect effects of nitrogen supply and disease source structure on rice sheath blight spread. Phytopathology 85:959-965.

29. Savary, S., Teng, P. S., Willocquet, L., and Nutter, F. W., Jr. 2006. Quantification and modeling of crop losses: A review of purposes. Annu. Rev. Phytopathol. 44:89-112.

30. Savary, S., Willocquet, L., Elazegui, F. A., Castilla, N., and Teng, P. S., 2000. Rice pest constraints in tropical Asia: Quantification of yield losses due to rice pests in a range of production situations. Plant Dis. 84:357369.

31. Slaton, N. A., Cartwright, R. D., Meng, J., Gbur, E. E., and Norman, R. J. 2003. Sheath blight severity and rice yield as affected by nitrogen fertilizer rate, application method, and fungicide. Agron. J. 95:1489-1496.

32. Tai, T., and Tanksley, S. D. 1990. A rapid and inexpensive method for isolation of total DNA from dehydrated plant tissue. Plant Mol. Biol. Rep. 8:297-303.

33. Tan, C. X., Ji, X. M., Yang, Y., Pan, X. Y., Zuo, S. M., Zhang, Y. F., Zou, J. H., Chen, Z. X., Zhu, L. H., and Pan, X. B. 2005. Identification and marker-assisted selection of two major quantitative genes controlling rice sheath blight resistance in backcross generations. Chin. J. Genet. 32:399405. (In Chinese with English abstract)

34. Venu, R. C., Jia, Y., Gowda, M., Jia, M. H., Jantasuriyarat, C.,·Stahlberg, E., Li, H., Rhineheart, A., Boddhireddy, P.,Singh, P., Rutger, J. N., Kudrna, D., Wing, Rod., Nelson, J. C., and Wang, G. L. 2007. RL-SAGE and microarray analysis of the rice transcriptome after Rhizoctonia solani infection. Mol. Genet. Genomics 278:421-431.

35. Wang, S., Basten, C. J., and Zeng, Z. B. 2007. Windows QTL Cartographer 2.5. Department of Statistics, North Carolina State University, Raleigh. (http://statgen.ncsu.edu/qtlcart/WQTLCart.htm)

36. Willocquet, L., Fernandez, L., and Savary, S. 2000. Effect of various crop establishment methods practiced by Asian farmers on epidemics of rice sheath blight caused by Rhizoctonia solani. Plant Pathol. 49:346-354.

37. Yan., J. Q., Zhu, J., He, C. X., Benmoussa, M., and Wu, P. 1998. Quantitative trait loci analysis for the developmental behavior of tiller number in rice (Oryza sativa L.). Theor. Appl. Genet. 96:267-274.

38. Zou, J. H., Pan, X. B., Chen, Z. X., Xu, J. Y., Lu, J. F., Zhai, W. X., and Zhu, L. H. 2000. Mapping quantitative trait loci controlling sheath blight resistance in two rice cultivars (Oryza sativa L.). Theor. Appl. Genet. 101:569-573.

39. Zuo, S., Yin Y., Zhang, L., Zhang, Y., Chen, Z., and Pan, X. 2007. Breeding value and further mapping of a QTL $q S B-11$ conferring the rice sheath blight utilized resistance. Chin. J. Rice Sci. 21:136-142. (In Chinese with an English abstract)

40. Zuo, S., Zhang, L., Wang, H., Yin Y., Zhang, Y., Chen, Z., Ma, Y., and Pan, X. 2008. Prospect of the QTL-qSB-9Tq utilized in molecular breeding program of japonica rice against sheath blight. J. Genet. Genomics $35: 499-505$ 